\title{
Defining engineering and technological literacies within the framework of lib- eral education: implications for the curriculum
}

\section{Dr. John Heywood, Trinity College Dublin}

John Heywood MA MSc LittD (Dublin) M.Litt (Lanacaster). Professorial Fellow Emeritus of Trinity College - The University of Dublin and formerly Professor and Director of Teacher Education in the University (1977 - 1996).

In addition to a higher doctorate he is the holder of a Masters degree in engineering education (MSc). $\mathrm{He}$ is a Fellow of the Royal Astronomical Society, a Fellow of the American Society for Engineering Education, a Senior Member of the Institute of Electrical and Electronic Engineers, a Fellow of the Chartered Management Institute, and a Licentiate and Fellow of the College of Preceptors.

His major studies are co-authored book "Analysing Jobs" about what engineers do at work; three editions of "Assessment in Higher Education" ; "Learning, Adaptability and Change; the Challenge for Education and Industry" and the American educational research award winning "Engineering Education: Research and Development in Curriculum and Instruction" published by IEEE/Wiley. He is a recipient of a Science, Education and Technology Division Premium of the London IEE for his contribution to engineering education. 


\title{
Defining engineering and technological literacies within the framework of liberal education: implications for the curriculum
}

\begin{abstract}
This paper develops a discussion begun in earlier papers between 2010 and 2012 by members of the Technological Literacy Division of ASEE. Technological literacy is a muddled concept for which reason members of the Technological Literacy Division led by John Krupczak have found it necessary to distinguish between two literacies- engineering and technological [1]. Accompanying this work, Mani Mina and others have also established a framework for the design and implementation of minor courses for the development of engineering and technological literacy among non-engineers [2]. It follows immediately from the argument that if engineering is necessarily a component of liberal education, and that if it is used as the focal point of a program of integrated study, the barriers that have been erected between liberal education and vocational education break down [3].

The first intention of this paper is to argue that the pursuit of technological literacy necessarily involves the pursuit of engineering literacy. Secondly, it demonstrates a model of technological literacy in which the two literacies are conflated. It is shown that the capabilities required by the model would also meet the requirements of such groups of employers as those who responded to the report from the Minnesota Office of Higher Education [3]. The third intention is to argue that reconciliation between the two literacies is more easily accomplished if new curriculum structures can be embraced. While it is understood that particular notions of curriculum structure are deeply embedded in a culture, it is argued that this embededness prevents a culture from reflecting on how it should respond to the explosion in knowledge that has occurred in the last century. This requires thinking outside the box about alternative curriculum structures.
\end{abstract}

A model curriculum for a college engineering and technological literacy program is described. Its framework is derived from elements of an experimental program in technology education designed for the transition year of Irish post-primary education. It was based on Whitehead's theory of rhythm in learning. Following a brief introduction the paper begins with a discussion of the differences between engineering and technological literacy

\section{Introduction; defining technological and engineering literacy}

Irrespective of the internet, knowledge in all areas of learning information continues to expand, and the internet makes it readily available. How it is handled, as the flow of papers published in IEEE Technology and Society and other journals show, is becoming increasingly problematic for knowledge is one of the most useful mechanisms of control that we have. Ease of information availability brings with it problems of ownership, intellectual property rights, privacy, and in extremis secrecy. Its handling also brings with it the need for higher order thinking skills in order for individuals and groups to cope with major moral issues as well as such things as new types of social relationship, psychological problems of IT addiction, and issues relating to personal feelings of control.

To deal with these problems the new knowledge area of technological literacy has been developed. Recently the idea of "engineering literacy" has been added to the concept of technological literacy. As might be expected this has caused some confusion.

How technological and engineering literacies are differentiated from each other is a matter of considerable importance. For example, Krupczak has pointed out (private communication) 
that many groups are now combining technological literacy and engineering literacy without much concern for distinguishing between the two. In this respect he draws attention to the fact that the US based International Technology Association has recently changed its name to the International Technology and Engineering Association (ITEA) [4]. This association has been involved in the development of a test of engineering and technological literacy as part of the National Assessment of Educational Progress (NAERP) test in the US [5]. Krupczak argues, perhaps controversially, that ITEA appended engineering to its name and mission with little outward indication of any change in its philosophical alignment. This is unsurprising since the Association is representative of school teachers, few of whom would have practised engineering. The problem underlines the value of the work undertaken by Krupczak and his colleagues in clarifying these terms as a basis for philosophical discussion.

Krupczak et al in their justification of the development of programs in engineering and technological literacy write that since "engineering concepts are pervasive in decision making within industry, government, education, health care" every citizen should be exposed in their education "to the central ideas and principles underlying our technological society" [1]. They find support for this view in the National Academy of Engineering's reports on "Technically Speaking: Why all Americans Need to Know more about Technology", and "Changing the Conversation. Messages for Improving Public Understanding of Engineering" [6].

No wonder then that a variety of courses in the guise of technological literacy have been introduced in the United States, or that there is much discourse about their content arising from the meaning that technology has for different groups of people. For example, a key issue for engineering policy makers is whether "technology" and "engineering" are synonymous "concepts". That this should be an issue is not surprising for, while there seems to be a public stereotype of the "technologist", a term that is often linked with "scientist" there seems to be no great perception of what it is that engineers do, or of the significance of the term "engineering". This may be regarded as harmful to the image of the engineer and consequently to the engineer's status in society. So a key question for engineers is where does engineering literacy fit into the muddle that has become technological literacy?

The Krupczak et al, paper grew out of an attempt by members of the Technological Literacy Division of the American Society for Engineering Education to respond to these issues. They set out to offer a "well-defined understanding of each of these areas" as "an essential first step in developing a means to promote these understandings in the undergraduate general education program". They presented several different ways of distinguishing between engineering and technological literacy. In one of them they argued that "engineering literacy is viewed as having a focus directed more toward the process of creating technological artefacts or systems." In contrast "technological literacy includes a broader view of products or results of the engineering process as well as the relation between technology and society". Krupzcak et al acknowledge that the "extent to which engineering and technological literacy form a subset of each other remains a topic for future discussion and investigation". On the basis of a process/product view of the issue Krupczak et al argue that a person who is 
technologically literate would have a "knowledge or ability to design, analyze or otherwise create the constituent parts of the....", and they give the example of the motor car. This may be compared with the broader view cited immediately above [1].

They point out that in spite of the fact that "technology can be viewed as identifiable things that result from engineering or related work" and should therefore "include some knowledge of these concepts, systems and processes" the "term engineering is not treated systematically by any of the technological literacy standards" [1].

The implications for the curriculum are profound. At one extreme, content arises from consideration of the impact of technology on society and individuals in particular, and at the other end of the spectrum, it arises from the needs of non-engineers to deal with engineers and engineering in their everyday activities. Given this scenario it is possible to envisage two (or more) entirely different programs in technological literacy. The question arises as to how these two might be linked in order to generate a common understanding of what it is to be engineering and technologically literate.

The purpose of this study is to argue that reconciliation between the two literacies is more easily accomplished if new approaches to curriculum structure can be embraced. While it is understood that the present notion of curriculum structure is deeply embedded in cultures, it is argued that this prevents a culture from reflecting in its programs the explosion of knowledge that has brought with it a much greater understanding of how individuals and teams learn, or the need for non-uniform blocks of knowledge that inform that understanding. A curriculum model that steps outside the plausibility structure will be presented.

\section{Engineering, technology, liberal education and the development of transferable skills}

In a paper to the Technological Literacy Division of ASEE in 2010 it was argued that engineering was necessarily a component of liberal education [7]. The defining characteristic of liberal education was "enlargement of mind". This "enlargement" was achieved by the capacity to perceive inter-relationships between the areas that comprise "universal knowledge" as it is currently understood. It follows that consideration of the "product" (technological literacy) without consideration of the "process" (engineering literacy) is not a liberal education. Furthermore, although not expressed in this way in the classical literature on the topic, this "enlargement" contributed to the development of the whole person, an aim that is often expressed by liberal educators.

The paper demonstrated how engineering problem solving and finding mirrored the process of liberal education. The solution of engineering problems required not only knowledge of engineering science and the mechanics of manufacturing but an understanding of the ways of thinking in such areas as the law, management as it embraced the social sciences, and philosophy. Evidently the model which is shown in exhibit 1 conflates the two literacies.

Subsequently, and in stark contrast, the National Governors Association (NGA) had published a report that recommended that State legislatures should pay much more attention 
to the provision of vocational education and much less attention to the support and development of traditional liberal education programs [8]. Naturally this brought strong objections from the liberal education movement. The recommendations in the NGA report were based on studies of future workforce requirements in the United States. These studies led the authors to believe that colleges were not offering programs of the kind that would readily meet the needs of the workforce. Other commentaries tended to support those conclusions that showed the characteristics of the workforce were changing. From an engineering perspective other data supported the view that while there was no great shortage of qualified engineers in the workforce they would have to be more adaptable and flexible and would have to possess a range of transferable skills [9].

In a later paper both the liberal and vocational educators were taken to task because, it was argued, there need be no real divorce between the academic and the practical [3]. Both were required for the completion of a liberal education. The model presented in exhibit 1 was used to support this thesis. It showed that technological/engineering literacy conceived as both an academic and practical study could provide a range, although not all, of the transferable skills (knowledge) required by the workforce in the future. However, it was clear that the model could not provide a liberal education without the inclusion of other subjects. This approach would change the role of technological literacy in a liberal arts program since it sought to integrate different ways of thinking into the liberal arts programme within the framework of engineering as conceived by the type of problems engineering seeks to solve.

\section{Technological literacy and engineering}

Inspection of the model in exhibit 1 shows that it conflates both dimensions of literacy. Its perspective combines both a product/process and broad view of the two literacies. Clearly, the products of engineering, the technologies (following Krupczak et al) interact at all levels of society. This can be seen from the influence of electro-mechanical devices in the kitchen and the impact they have had on families, or at a societal level, or for example, in the concern that communities have for processes like fracking which enable large quantities of gas to be extracted from shale. At the micro-level changes in kitchen technology or for that matter electronics in the home are adapted to without much thought. Not so when a community is faced with fracking. While cell (mobile) phones were quickly accepted some communities reacted unfavourably to the systems antennas because of fears of cancer. To persuade communities engineering explanations for the acceptance of the technology, which they will be expected to take on trust, will be given. For them to make a rational decision they will have to have some knowledge of risk and some understanding of the engineering together with an ability to synthesize the two. In a word, they will need to be engineering and technologically literate. 
Exhibit 1. Model of the way in which engineering and technology support society and the economy [10].

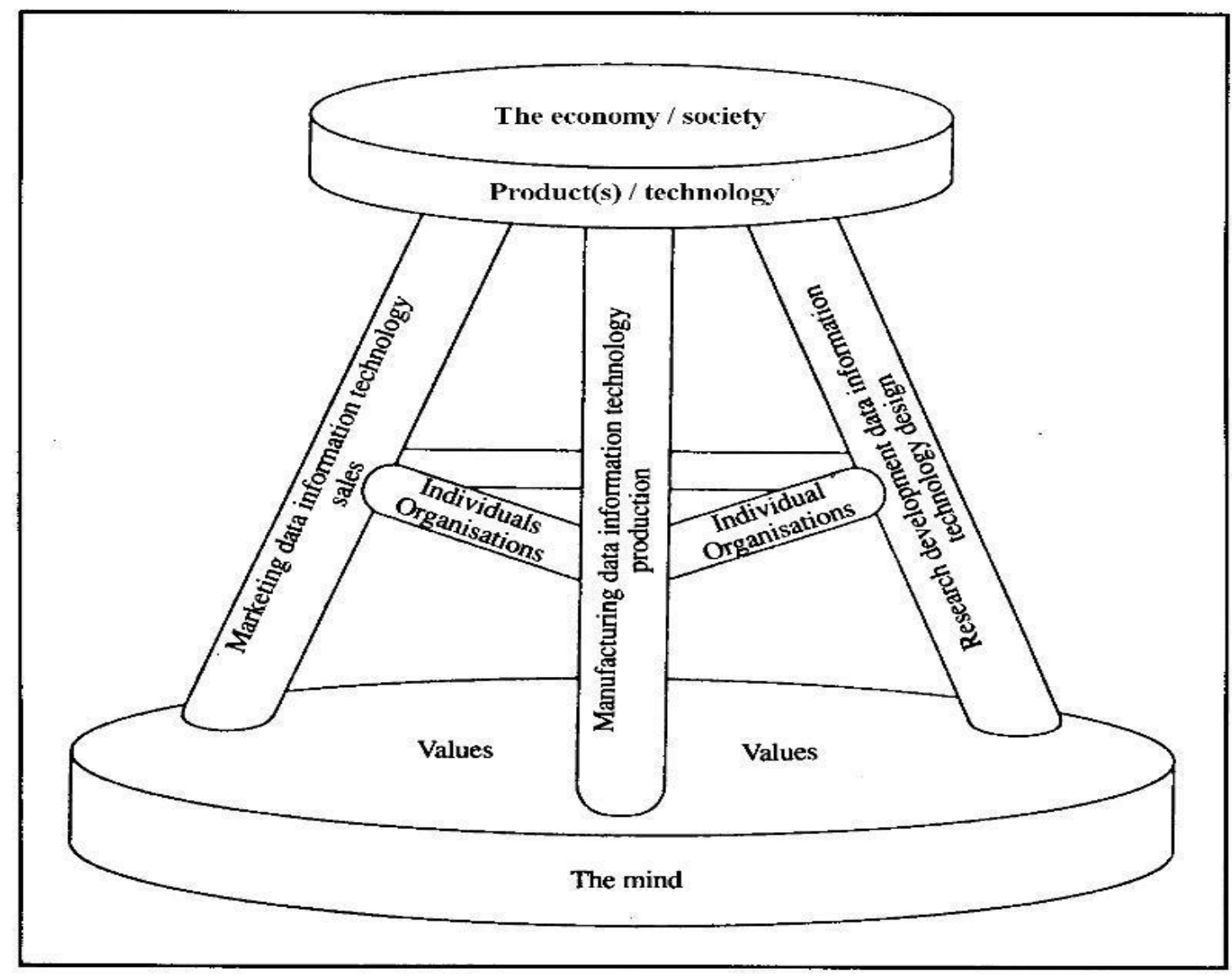

The central issue for the curriculum is how much knowledge of engineering is required and can it be gained without having to do a substantive four year program? But technology has other, perhaps more insidious effects in the home. For example children are able to use the internet to view pornography. For some parents there is evidently no moral issue about viewing pornography but for the majority there is. While there is no need for a detailed understanding of technology to resolve this issue there is clearly a need to understand our value system as well as those of others. So any program in technological literacy has to function at different levels of apprehension and with different dimensions of knowledge ranging from the technological to the philosophical.

There is, however, another dimension of technological literacy that relates to engineering in quite a different way. Inspection of exhibit 1 shows that the engineering processes that take place in the legs of the stool have to be bound together by organizational structure and it inevitably involves people in some function or another. Thus, the process of engineering is carried out by technological systems of two kinds: (1) the systems that manufacture and (2) the systems that cause and control the manufacture. Both are social and technical in the same 
way that technology is part of a more general social-technical system. Following Krupczak et al engineering is the process of realising a design as a technology which is used in society. It is for this reason that this model of engineering and technology necessarily conflates the two literacies, while at the same time showing the different educational needs that have to be satisfied.

At one end of the curriculum spectrum are traditional engineering science based courses that rely heavily on a knowledge of physics and mathematics. At the other end are programs in technological literacy that rely on methods in the social sciences and philosophy and make little or no reference to engineering processes. They can be at either the level of a full undergraduate program, or a short single unit intended to create awareness of the issues involved. Neither arrangement fulfils the requirements for a liberal education except in so far as they insure that the interrelationships between the subjects (courses) that make up the programs are understood. A major criticism of engineering programs is that this has not been the case although some schools have tried to ensure that this is done. The question is whether or not there is a way of developing a course that would provide the foundation of a liberal education that brings together the academic and vocational (practical) and links the literacy of engineering with that of technology?

\section{The "educational and social politics of" engineering and technological literacy}

It is fairly easy to list a number of courses that derive from the model shown in exhibit 1. To name but several: engineering design, economics, industrial psychology and sociology, manufacturing, and philosophy. The knowledge available to all these segments is large and learning can be at various levels of depth which is determined to some extent by a person's ability and previous knowledge. When these knowledge dimensions are combined it is easy to imagine a substantive degree program in engineering/technological literacy. Equally it is easy to perceive that the kind of teaching and learning necessary to bring about the outcomes of engineering/technological literacy would have to be very different to that undertaken in the same courses when treated as separate entities within a traditional program. Both level and approach would be different since the overall goal is the achievement of a synthesis.

At the present time it would seem to be politically difficult to achieve such a program because it lies outside the plausible. Nevertheless, in the United States it would appear that curriculum developments are being made that could ultimately lead to the development of such a programme. For example Gustafson and his colleagues have undertaken a major study of minors as a means of developing technological and engineering literacy for non-engineers [11], [12]. Their intention was to provide a framework for the development of minor programs. Included in their study are a standard set of outcomes which it is possible to conceive as being as applicable to a full degree programme as they are to a short course. These curriculum developers are therefore, providing a base on which a larger scaffold could be built. Moreover the framework is within the educational plausibility structure. That is, within a structure where further developmental change is possible. 
A pre-requisite of major curriculum change is that all the parties involved buy into the change. This means that ideas have to be presented and developed and themselves be changed in the process [13]. The essential purpose of this paper is to demonstrate how the mathematician/philosopher Whitehead's model of the process of education envisages a different curriculum structure that can bring together the two literacies [14]. At this time it lies outside the plausibility structure.

\section{An alternative curriculum structure.}

In the middle nineteen seventies the Minister for Education in Ireland approved a project that would allow a few schools to develop a transition year between the junior cycle of postprimary education when students take a public examination called the Junior Certificate (15+ years) and the first year of the two year programme for the Leaving Certificate (17+ years). The idea was that students should be freed from their studies for examinations and that they should undertake studies that would help their personal and career development. They would continue with some traditional studies but the focus of the year would be on non-traditional studies and include work and community experience. By 1986 the Curriculum and Examinations Board had published the list of outcomes (skills and competencies) shown in exhibit 2. The list is very similar to that published by the Minnesota Office for Higher Education of the top skill needs required by Minnesota employers (exhibit 3). Since then various Ministers have increased the numbers of schools allowed to offer the scheme and now large numbers of students participate. There is some evidence that those who participate in the transition year perform better in their Leaving Certificate examinations. Within certain limits of approval the schools are largely free to develop their own schemes. It is therefore an ideal scheme with which to experiment with the curriculum and the Christian Brothers who own a large number of secondary schools (12 to 18 years) took advantage of this opportunity. One of their endeavours in association with this writer was to develop a program for technology. Although they tested some of the components of the programme, for political reasons, it was not completed. The program design was based on Whitehead's rhythmic theory of learning and motivation [15].

\section{Whitehead's philosophy of rhythm in the educational process.}

Whitehead's philosophy of education is based on the concept of rhythm in life. "Life is essentially periodic... There are also subtler periods of mental growth with their cyclic recurrences, yet always different as we pass from cycle to cycle, though each of the subordinate stages are reproduced in each cycle. That is why I have chosen the term rhythmic as meaning essentially the conveyance of difference within a framework of repetition" [14, p 27]. Whitehead considered that there were three stages in the cycles of education. The first of them he called Romance. This is the stage of first apprehension. "The subject matter has the vividness of novelty: it holds within itself unexplored connexions with possibilities half-disclosed by glimpses and half-concealed by wealth of material". In this stage knowledge is not dominated by systematic procedure. "Such system as there must be is 
- Have been exposed to a broad, varied and integrated curriculum and have developed an informed sense of his/her own talents and preferences in general educational and vocational matters (transition skills)

- Have developed significantly the basic skills of literacy and numeracy and oracy. (It is assumed that most students will have developed these skills before the end of the junior cycle, but specific reinforcement for some will be needed through TYO) (literacy and numeracy skills).

- Have developed confidence in the unrehearsed application of these skills in a variety of common social situations (adaptability).

- Have experienced as an individual or part of a group, a range of activities which involve formal and informal contacts with adults outside of the school context (social skills).

- Have developed confidence in the process of decision making, including the ability to seek out sources of support and aid in specific areas. (decision making).

- Have developed a range of transferable thinking skills, study skills and other vocational skills (learning skills).

- Have experienced a range of activities for which the student was primarily responsible in terms of planning, implementation, accountability and evaluation, either as an individual or a partner in a group. ( problem solving)

- Have developed appropriate physical and manipulative kills in work and leisure contexts (physical).

- Have been helped to foster sensitivity and tolerance to the needs of others personal relationships (interpersonal/caring).

- Have been enabled to develop an appropriate set of spiritual, social and moral values (faith; morals)

- Have had opportunities to develop creativity and appreciation of creativity in others (aesthetic).

- Have developed responsibility for maintaining a healthy lifestyle, both physical and mental (health).

- Have developed an appreciation of the physical and technological environments and their relationship to human needs in general (environment).

- Have been given an understanding of the nature and discipline of science and its application to technology through the processes of design and production (science/technology).

- Have been introduced to the implications and applications of information technology (information technology).

Exhibit 2.The aims of the transition year expressed in terms of the skills and competencies that should be developed in Planning, Introducing and Developing Transition Year Programmes. Guide Lines for Schools (1986). Interim Board for Curriculum and Examinations. Dublin. The Board stated that the list was not exhaustive and that new ones may emerge through the experience of schools in offering the curriculum. 


\section{Attributes (most frequent ratings of 'very important' by employers.}

Professionalism (punctuality, time management, attitude).

Self direction, ability to take initiative.

Adaptability, willingness to learn.

Professional ethics, integrity.

Verbal communication skills.

Most frequent ratings of 'not at all' or 'not very important' Last 5.

Advanced mathematical reasoning (linear algebra, statistics, calculus).

Technical communications.

Fluency in a language other than English.

Knowledge of specific computer applications required for the job.

Application of knowledge from a particular field of study.

Other

Capability for promotion and advancement.

Creativity.

Ability to work in a culturally diverse environment.

Ability to work in teams.

Written communication skills.

Basic mathematical reasoning (arithmetic, basic algebra).

Critical thinking and analysis.

Problem solving, application of theory.

General computer skills (word processing, spread sheets).

Knowledge of technology /equipment required for job.

Exhibit 3. A re-arranged summary of the top skill needs of Minnesota Employers. Minnesota Office of Higher Education. Minnesota measure. 2009 Report on Higher Education Performance. Cited in full in Sparks, E and M. J. Waits (2011) Degrees for what jobs? Raising Expectations for Universities and Colleges in a Global Economy: p 27. National Governors Association.

excitement consequent on the transition from the bare facts to the first realisations of the import of unexplored relationships" [14, p 28]. The second stage is that of precision. "In this stage width of relationship is subordinated to exactness of formulation. It is the stage of grammar, grammar of language and grammar of science. It proceeds by forcing the students' acceptance a given way of analysing the facts bit by bit. New facts are added, but they are the facts which fit into the analysis." [14, p 29].

"The final stage of generalisation is Hegel's synthesis. It is a return to romanticism with added advantage of classified ideas and relevant technique. It is the fruition which has been the goal of precise training." [14, p 30].

Whitehead argued that education should be a continual repetition of such cycles. While he uses the term stage it is not used in the same sense as Piaget whose stages were relatively fixed. Nevertheless it is useful to think of both long cycles and shorter and very short cycles within them. For example primary (elementary) education is essentially (or should be) a stage of romance. Whitehead praised the Montessori approach to early childhood education. But he also pointed out that an infant's first stage of precision is the mastering of spoken language. 
This view is consistent with those who believe that young children are capable of handling the "big" ideas of philosophy and should be taught philosophy in their own terms [16].

Similarly post-primary (high school) education is primarily a stage of precision which is continued through university to be completed by the stage of precision. The speed at which students' accomplish these cycles in a subject is very much a function of their motivation and the way in which subjects are taught. But for Whitehead education "must essentially be a setting in order of a ferment already stirring in the mind: you cannot educate the mind in vacuo. In our conception of education we tend to confine it to the second stage of the cycle of precision. But we cannot so limit our task without misconceiving the whole task. We are concerned alike with the ferment, with the acquirement of precision, and with the subsequent fruition" [14, p 29].

It is a criticism of higher education that it confines itself to analysis (precision). It takes no cognisance of the need to motivate students at the beginning of their studies, that is, to create a stage of romance; neither has it advanced them through a stage of generalisation. Students who are faced with studying a new subject should be allowed to explore the range of the subject. Romance is clearly a stage that should provide a variety of topics with some overall focus (integration) in mind that will motivate a student to want to be precise in a variety of topics. It is not without significance that several engineering educators have in recent years called on their colleagues to take note of what happens in primary (elementary) teaching [17]. There has also been widespread recognition among engineering educators in the US that the way in which freshman courses are designed has a powerful influence on the motivation of students to remain in engineering [18]. The initial stages of programs in engineering/technological literacy however short or long need to be oriented toward a stage of romance. At the other end of degree programs there is the hope that capstone projects provide the generalisation that is necessary. The project method is of course, widely used in primary education. Given that the topic is carefully chosen it can be an ideal method for integrating knowledge.

It has been pointed out that often engineering students find little connection between the different knowledge units that make up engineering courses. In consequence there have been some attempts to give engineering courses greater coherence [19]. Whitehead's philosophy of education is that learning is a search for coherence which comes about in the stage of generalisation in each rhythmic cycle. There is no doubt that the interface between engineering and society in technology brings about complex problems that demand higher level thinking skills in analysis, synthesis and judgment. In an appropriately designed course the student will be exposed to the excitement of new possibilities and through grammar develop the skill of precision (analysis), and finally through the romance of new and complex sometimes fuzzy problems develop skill in synthesis and judgement. Such a course would bring a student to the higher stages of learning that theorists like Perry, and King and Kitchener believe are not accomplished in higher education [20]. 
While Whitehead only distinguished between the grammars of language and science it is clear that an engineer has to learn many different grammars or languages [21].Engineering literacy and technological literacy are different languages: one of the features that distinguishes them are their grammars and Krupczak and his colleagues have gone some way to explain them. What is clear from their analysis is that while it would be possible to design a program in technological literacy that demands little knowledge of engineering this would be to its detriment. Programs of engineeringl/technological literacy will inevitably conflate the two.

\section{A model curriculum}

Talk of grammar inevitably raises questions of level or depth of understanding. For example, "awareness" is a very limited objective, and does not really meet that goal of a liberal education which demands that an individual should understand a variety of ways of thinking, and acquire a range of transferable skills. Those goals will only be met if there is some kind of experience. A general outcome goal might, therefore be, to experience the different ways of thinking that are necessary for the study of the engineering process and its technological outcomes. One possible way of obtaining this goal is to create a project large in scope and time that requires the student to pursue other areas of knowledge on a" just in time" basis. Attempts have been made to model such a process but they would be difficult to implement.

If, however Whitehead's model is used then it should be possible to go beyond awareness to some understanding of the ways of thinking in the variety of subjects that the concept of engineering and technology as illustrated in the first exhibit demands. One attempt to do this is shown in exhibit 4. It was designed for the transition year in Ireland that was described above. The model was derived from exhibit 1 which was accompanied by the objectives listed in the 2010 paper (exhibit 5). There is a close relationship between them and the list of outcomes suggested by Krupczak et al (exhibit 6) although the former leans towards engineering literacy and the latter toward technological literacy.

Within the context of liberal education the model is limited to show the structure for engineering and technology. It is assumed that other areas of knowledge will be considered in parallel, and this would be the case for any university course in liberal education that is focused on engineering and technological literacy.

Some of the courses shown in the model were developed and trialled but "politics" intervened and brought the work to a halt. An independent evaluation of the work was carried out by Professor Dr Heiko Steffens of the Technical University of Berlin [22] but other studies were also completed that were published (see below). The design follows Whitehead's three stages but assumes students will experience other complete cycles in each of the stages.

The first stage of romance is characterised by short intensive course in manufacturing technology and materials and processes in a custom built laboratory. The course designed and implemented by Owen took place over two weeks, the students being in attendance for 5 hour days. The students comprised an equal mix of boys and girls aged 15+. It was based on a 
series of projects the final one being to use a CAD system to design and manufacture a chess piece. It was the opinion of Owen and the course director that the girls performed better than the boys, but that all the participants enjoyed and learnt from the course [23]. Ideally the course in manufacturing would have been improved if it had been accompanied by some activities designed to help the students acquire a variety of problem solving techniques. This was not possible. However a separate intensive course of two weeks duration with a different group of students that concentrated on the development of skill in technical investigation and quality control, showed how the range of problem solving techniques could be extended. This course, devised and implemented by D. T. Kelly, was also judged to be a success [24].

For the stage of precision, on separate occasions, teachers in a network of schools designed and implemented courses in management [25] and business [26]. Teachers in this network also designed and implemented a course in the psychology of learning [25]. These experiments took place within the framework of a substantial period of training. In the case of electronics the information available from the teacher training course would have been sufficient to for the teachers to derive a school program in that subject. The teacher training courses for teachers in management had as their 'key' concept the "organization as a learning system" which was used to integrate the sociology and psychology of organizations with attention to economics and finance.

Although the model shows much attention to the broad issues of technological literacy in the stage of precision it does not respond to the need for romance or generalization in this area. The model would have to have been adapted to ensure these stages were part of the curriculum process. However, the socio-technical system that is the organization (ie the technology of organization) is catered for in all stages of the model.

Had the model functioned it would have had to have ensured that it met all the requirements listed in exhibit 2. It would in consequence have met many of those required by the Minnesota employers (exhibit 3). Similarly the detailed technical objectives of the program have many similarities with those listed by Krupczak et al. (see exhibits 5 and 6).

\section{Comment}

This paper has developed the discussion begun in earlier papers. Its first intention has been to show that the pursuit of technological literacy necessarily involves the pursuit of engineering literacy and the two are conflated in the model presented in exhibit 1. Its second intention has been to argue that traditional program structures need to be much more flexible if an integrated study based on active methods of learning is to be achieved. It has been shown that the capabilities required for the course as run would also meet the requirements of such groups of employers as those who responded to the report of the Minnesota Office of Higher Education. Coincidentally the paper reinforces the work of Krupczak and his colleagues in clarifying the differences between engineering and technological literacy while at the same time pointing out that the one cannot exist without the other and vice-versa. It also demonstrates the value of philosophical theories in the design of the curriculum. 


\section{Acknowledgement}

I am grateful to Dr John Krupczak and Dr Alan Cheville for their helpful advice in completing this paper, as well as to the unknown reviewers for their comments.

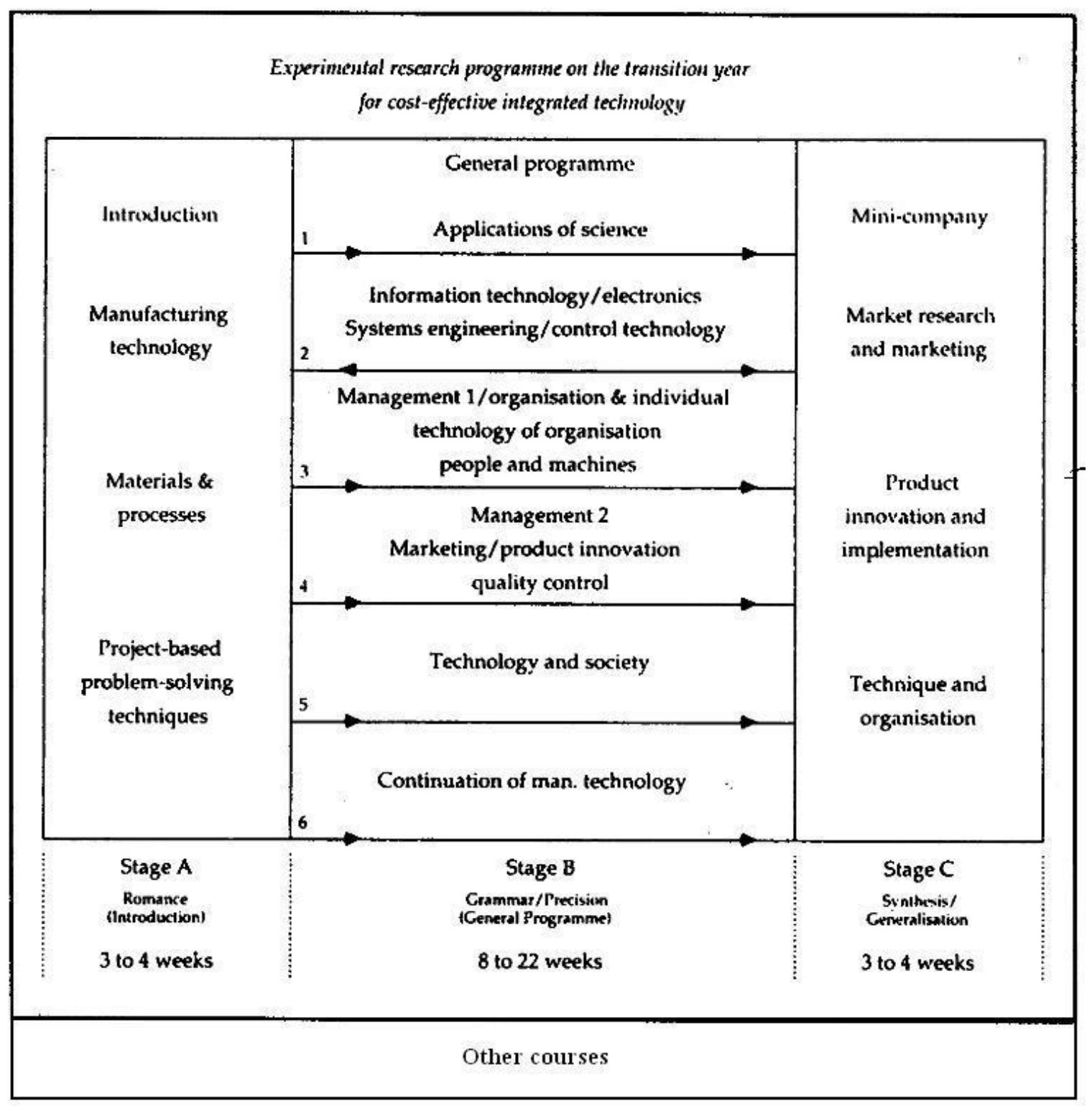

Exhibit 4. Whiteheads stage model of educational development applied to a program for teaching engineering and technological literacy. 
Some aims and objectives for engineering literacy.

The prime aim of a course in engineering literacy would be to show the relevance of engineering to the solution societal problems and to develop capabilities in the judgement of the merits of solutions that are proposed. It would involve showing the students what engineers do when they are doing engineering, an aim that implies giving them practical experience of designing and making things.

For engineering this aim may also be expressed in terms of the ability to comprehend papers of the type that appear in IEEE Technology and Society and IEEE Spectrum but especially articles and comments in quality newspapers.

\section{The materials and activities used should}

1. illustrate the structure of thought and methods of inquiry in engineering and how it differs from science especially physics;

2. illustrate the centrality of design in engineering;

3. provide an insight into the processes of engineering to such a point that students would be able to increase their understanding unaided when circumstances required it;

4. enable them to compare the structure of thought and methods of inquiry in engineering to those of their own subjects and interests;

5. $\quad$ consider the implications of the view that engineering design is a social process;

6. help them gain an insight into their own moral purpose.

From inspection of these objectives it would appear that a course in engineering literacy would consider the following:

1. The sources of engineering ideas and problems (creativity, invention and innovation).

2. The design and manufacturing cycle. Modelling

3. The potential and limitations of materials and processes

4. The potential and limitations of machines for the manufacturing process.

5. The determinants of cost, quality and morality in engineering and manufacturing processes (optimization).

6. The determination of risk and safety in engineering taking into account moral purpose. ${ }^{31}$

7. The significance of product design in engineering, and design in styling.

8. The potential of electronic devices in information technology, and control technology.

9. The assistance which the application of scientific principles can give to each stage of the engineering activity.

10. The significance of industry in wealth creation and the roles of the entrepreneur and innovator.

11. The significance of the market in product design and manufacture.

12. The voting contribution of the individual in a democratic society as a determinant of prevailing and future socio-economic models.

13. The understanding of human behaviour and factors that contribute to personal and interpersonal competence

Exhibit 5. From Engineering at the Crossroads: Implications for Educational Policy Makers. Distinguished Lecture. (2012) American Society for Engineering Education (pamphlet). Developed from a list in Heywood, J (1986). Toward technological literacy in Ireland: an opportunity for an inclusive approach in Heywood, J and P. Matthews (eds). Technology, Society and the School Curriculum. Practice and Theory in Europe. Manchester, Roundthorn. 


\section{A. Knowledge}

1. articulate the pervasiveness of technology in everyday life.

2. Define basic engineering concepts and terms, such as systems, constraints and trade-offs.

3. Describe the nature and limitations of the design process.

4. Explain some of the ways technology shapes human history and people shape technology.

5. Compare the benefits and risks that all technologies entail, some that can be anticipated and some that cannot.

6. Identify the effects of technology on the environment.

\section{B. Ability to engage.}

7. Describe the development and use of technology and evaluate trade-offs including a balance of costs and benefits both economic and social.

8. Identify technology that appropriately reflects the values and culture of society for which it is intended.

9. Give examples of relat9onships among technologies and connections between technology and other fields of study.

\section{Responsibility}

10. Can identify and analyze professional, ethical and social responsibilities as related to technology.

11. Participates appropriately in decisions about the development and use of technology.

12. Demonstrates an interest and ability in life-long learning and self-education about technological issues.

\section{Capabilities}

13. Formulate pertinent questions, of self and others regarding the benefits and risks of technologies.

14. Obtain and interpret information about new technologies.

15. Discriminate the role of problem solving for troubleshooting, invention, innovation, research and development.

16. Function effectively within teams of varying technological expertise.

17. Communicate effectively, both orally and in writing, regarding technological issues.

18. Think critically and creatively regarding technological issues including an ability to assess, rank, or to compare proposed designs on the basis of desired outcomes, consequences and constraints.

Exhibit 6. Educational outcomes for technological literacy programs in Krupczak, J, Mina, M., Gustafson, R. J., Young, J. F and S. VanderStoep. Minaors as a means of developing Technological and Engineering Literacy for non-engineers. Proceedings Annual Conference, American Society for Engineering Education. paper AC 2012-4696. Table 1. 


\section{Notes and references.}

[1] Krupczak, J., Blake, J. W., Disney, K. A., Hilgarth, C. O. Libros, R., Mina, M., and S. R. Walk (2012) Defining Technological Literacy. Proceedings Annual Conference American Society for Engineering Education. Paper AC 2012-5100.

[2] (a) Mina, M (2007). Minor in engineering studies. Teaching engineering concepts to non-engineering students-work progress. Proceedings of the Frontiers in Education Conference, T3H- 1 \& 2.

(b) Mina, M.J., Krupczak, J. J., Gustafson, R., and J. Young (2010). Expanding technological literacy through engineering minors. Proceedings Annual Conference of the American Society for Engineering Education. AC 2010-1140.

[3] Heywood, J (2012). Engineering at the Crossroads: Implications for Educational Policy Makers. Distinguished lecture at the Annual Conference of the American Society for Engineering Education. Pamphlet.

[4] International technology Association, Reston VA. Also produced the Standards for Technological Literacy (2000).<,http://www.iteaconnect.org/TAA/Publications/TAA_Publications.html>

[5] National Assessment of Educational Progress (2014) NAEP Technology and engineering literacy assessment and items specifications- Pre-publication edition.

http://www.edgateway.net/es/naepsci/view/naep_nav/9

[6] (a) Pearson, A and T. Young (eds) (2002). Technically Speaking. Why all Americans need to know more about Technology. Washington, DC. National Academies Press.

(b) Committee on Public Understanding of Engineering Messages. (2008). Changing the Conversation: Messages for Improving Public Understanding of Engineering. Washington, DC., National Academies Press.

[7] Heywood, J (2010) Engineering literacy: A component of liberal education. Proceedings American Society for Engineering Education Annual Conference. AC 2010-1505.

[8] Sparks, E and M. J. Waits (2011). Degrees for what Jobs? Raising expectations for Universities and Colleges in a Global Economy. Washington, DC. National Governors Association.

[9] See for example Heywood, J (2012) ref.3. See also OECD (2012) Employment Outlook 2012. Paris. OECD.

[10] Adapted from Heywood, J (1986). Toward technological literacy in Ireland: an opportunity for an inclusive approach. In Heywood, J and P. Matthews (eds) Technology, Society and the School Curriculum. Practice and Theory in Europe. Manchester, Roundthorn.

[11] Gustafson, R., Mina, M., Krupczak, J., and J. Young (2011). Educational objectives and outcomes for technological literacy programs at college level. Proceedings of the Annual conference of the American Society of Engineering Education. Paper AC 2011-182.

[12] Krupczak, J., Mina,. M., Gustafson, R. J., Young, J. E. and S. VanderStoep (2012. Minors as a means of developing technological and engineering literacy for non-engineers. Proceedings Annual Conference of the American Society for Engineering Education. Paper AC 2012-4696. 
[13] See general sociology of the idea in Walgrave, J-H. (1960) Newman the Theologian. London Geoffrey Chapman commenting on Newman's view of how ideas develop in society pp $171-179$.

[14] Whitehead, A. N (1932). The Aims of Education and other Essays. London, Ernest Benn (1959 edition).

[15] Owen, S and J. Heywood (1990). Transition technology in Ireland. International Journal of technology and Design Education, 1, (1), 21 - 32.

[16] Lipman, M and A. M. Sharp (eds) (1978). Growing up with Philosophy. Philadelphia, Temple University Press. See also Matthews, G. B (1980). Philosophy and the Young Child. Cambridge, MA., Harvard University Press.

[17] Crynes, B. L and D. A. Crynes (1997). They already do it: common practices in primary education that engineering education should use. Proceedings Frontiers in Education Conference , 3, 12 -19.

[18] Anderson-Rowland (1998). The effects of course sequence on retention of freshmen engineering students: when should the introductory engineering course be offered? Proceedings Frontiers in Education Conference. T3A - 6 pages.

[19] Culver, R. S and J. T. Hackos (1982). Perry’s model of intellectual development. Engineering Education, 73, (2), 221, - 226.

[20] (a) Perry, W. B (1970) Forms of Intellectual and Ethical Development in the College years. New York, Holt, Rienhart and Winston (b) King, P. M and K. S. Kitchener (1992). Developing Reflective Practice. San Fransisco, Jossey Bass.

[21] Bucciarelli, L, L (2003). Engineering Philosophy. Delft, Delft University Press.

[22] Steffens, H (1991). Re-training teachers for the new technology education programmes in Ireland. International Journal of Technology and Design Education, 2, (2), 3 - 35.

[23] loc.cit ref 12.

[24] Kelly, D. T and J. Heywood (1996). Alternative approaches to K-12 technology illustrated by an experimental course in technical investigations. Proceedings Frontiers in Education Conference. 383 393.

[25] Heywood, J and M. Murray (2005) Curriculum - Led staff development: Towards curriculum and instructional leadership in Ireland. Bulletins of the European Forum on Educational Administration. No $4.3-97$.

[26] Murray, M (1991). An Evaluation of an Introductory Programme in Management. Ph. D. thesis. Dublin, University of Dublin. 